\title{
田
}

\section{MULHERES E SELETIVIDADE PENAL: “RAÇA” E CLASSE NO ENCARCERAMENTO FEMININO}

\author{
WOMAN AND PENAL SELECTIVITY: “RACE” AND CLASS IN FEMALE IMPRISIONMENT
}

\author{
Ana Clara Gomes Picolli* \\ http://orcid.org/0000-0002-9173-2391 \\ Silvana Marta Tumelero** \\ https://orcid.org/0000-0001-9104-4276
}

\begin{abstract}
RESUMO
O presente artigo tem como centralidade compreender alguns elementos das atuais condições e conjuntura do aprisionamento de mulheres no Brasil. Para isso, traz as principais características da população prisional feminina, visando refletir sobre os determinantes sociais e históricos que marcam estas mulheres. Conjuntamente, aborda-se temas relevantes para o desvelamento dos conceitos sustentados pelo Estado penal, demonstrando a contradição dos processos de criminalização de sujeitos. Busca-se suscitar uma reflexão sobre a seletividade penal do Estado, onde a criminalização perpassa marcadores de classe social, sexo, sexualidade, "raça", entre outros. Esta seletividade demarca sujeitos puníveis e a perpetuação do encarceramento em massa da população negra. Tendo por base teórica o materialismo histórico, tal qual a compreensão de demais estruturas que compõe a sociabilidade capitalista, como o racismo, sexismo e outras opressões que marginalizam corpos não hegemônicos, o artigo intenciona contribuir com o debate sobre o tema, no campo do Serviço Social.
\end{abstract}

\section{PALAVRAS-CHAVE:}

Mulheres em cárcere. Prisões. Seletividade penal. Cultura punitiva.

\section{ABSTRACT}

The present article seeks to understand some elements of the current conditions and juncture of the imprisonment of women in Brazil. To do so, we brought the main characteristics of the female prison population in order to reflect about the social and historical determinants that mark these women. We also discuss relevant issues to unveil the concepts sustained by the penal State, which demonstrates the contradiction on the cases of the criminalization of individuals. We sought to raise a reflection on the selectivity of the penal State where criminalization ranges through markers of social class, gender, sexuality, "race", among others. Such selectivity distinguishes punishable subjects and perpetuates the mass incarceration of the black population. Having as theoretical basis the historical materialism, as well as the understanding of other structures that compose capitalist sociability, such as racism, sexism and other

\footnotetext{
* Graduanda de Serviço Social da Universidade Federal do Paraná, Setor Litoral. (UFPR, Matinhos (PR), Brasil), Rua Jaguariaíva, 512, Caiobá, Matinhos (PR), CEP: 83260-000. E-mail: <anaclaraggpicolli@gmail.com>.

${ }^{* *}$ Assistente social. Doutora em Serviço Social. Professora da Universidade Federal do Paraná, com atuação na Câmara de Graduação do Setor Litoral. (UFPR, Matinhos (PR), Brasil), Rua Jaguariaíva, 512, Caiobá Matinhos (PR), CEP: 83260-000. E-mail: <siltumelero.ufpr@gmail.com>.
}

DOI 10.22422/temporalis.2019v19n38p164-179 Commons Atribuição 4.0 Internacional (https://creativecommons.org/licenses/by/4.o/deed.pt_BR), que permite copiar e redistribuir o material em qualquer suporte ou formato, bem como adaptar, transformar e criar a partir deste material para qualquer fim, mesmo que comercial. O licenciante não pode revogar estes direitos desde que você respeite os termos da licença. 
oppressions that marginalize non-hegemonic bodies, this article intends to contribute to the debate on that matter in the area of Social Service.

\section{KEYWORDS}

Imprisoned women. Prisons. Penal Selectivity. Punitive Culture.

É necessário, urgentemente, fechar as comportas do sistema penal e estancar as "veias abertas" do sistema prisional brasileiro com a adoção de medidas efetivas de desencarceramento, de abertura do cárcere para a sociedade e de mitigação de danos enquanto houver prisões (PASTORAL CARCERÁRIA, 2014, p. 8).

\section{INTRODUÇÃO}

O Brasil é, atualmente, o $4^{\circ}$ país com maior população prisional feminina do mundo (BRASIL, 2018). Dados do Levantamento Nacional de Informações Penitenciárias (INFOPEN) explicitam que entre os anos 2000 a 2014 a população carcerária feminina cresceu em 567\%. Este quadro chama a atenção para o processo progressivo de encarceramento de corpos femininos em nosso país. Esses dados têm suscitado algumas questões em nosso processo de pesquisa acadêmica que teve início em 2016: quem são essas mulheres encarceradas? Ao que respondem as rés do judiciário brasileiro? Como a prisão atua sobre estes corpos? A esses questionamentos, pretendemos, com o presente artigo, trazer algumas respostas e produzir novas reflexões.

Este artigo tem por objetivo demonstrar os determinantes sociais e as condições prisionais de mulheres em privação de liberdade no Brasil. Para isso, utiliza-se de fontes secundárias de informação, como dados estatísticos do Levantamento Nacional de Informações Penitenciárias e outras organizações que disponibilizam materiais e estudos sobre o cárcere e sua materialização no país. Além disso, foi realizada uma revisão bibliográfica acerca de prisão, seletividade penal, o aprisionamento de mulheres e os determinantes da criminalização conduzida pelo Estado sob determinados corpos.

O trabalho está dividido em dois tópicos. O primeiro trata de apresentar brevemente dados que demonstram as características socioeconômicas de mulheres em situação de prisão. Este tópico busca trazer o atual perfil da mulher encarcerada no Brasil, suas características e condições enquanto trabalhadoras em privação de liberdade. No segundo item é analisada a atuação do sistema penal através das prisões que demarcam determinados sujeitos como sendo mais vulneráveis à punição, instaurando o que se denomina de seletividade penal. Esta seletividade, como será exposta, se utiliza de marcadores sociais como sexo/gênero, classe social, "raça", sexualidade, geração, entre outros, que determinam a vivência de sujeitos e a perpetuação de privilégios da branquitude através de discursos e práticas que fortalecem a manutenção de uma cultura punitiva.

As reflexões apresentadas neste trabalho têm como referencial epistemológico o materialismo histórico, que contribui para o desvelamento da realidade a partir da apreensão do real através de suas contradições e de seu desenvolvimento histórico, tendo

\footnotetext{
${ }^{1}$ Utiliza-se a categoria raça a partir da "[...] concepção de raça social [...]", entendida como "[...] a construção simbólica, cultural, e sobretudo política, que se tem feito do biológico como estratégia que sustenta o racismo" (CURIEL, 2002, p. 97, tradução nossa).
}

Temporalis, Brasília (DF), ano 19, n. 38, p. 196-211, jul./dez. 2019. | ISSN 2238-1856 
as classes sociais como determinante dos lugares em que grupos de indivíduos historicamente ocupam no processo de produção social. Complementarmente, utiliza-se de estudos produzidos por teóricas negras para discussão do racismo, enquanto sistema político para manutenção de privilégios da branquitude. Na busca de melhor compreender o aparelho punitivo do Estado as referências utilizadas encontram-se em obras de Michel Foucault.

Tais reflexões mostram-se urgentes no atual cenário das prisões brasileiras, aliado à crescente propagação de discursos conservadores, advindos de representantes políticos, que dão ensejo a práticas e discursos de ódio que tendem a corroborar com a violência de corpos que não correspondem as normatizações da ordem burguesa.

\section{BREVE PANORAMA SOBRE A POPULAÇÃO PRISIONAL DE MULHERES NO BRASIL}

Os dados sobre o encarceramento no Brasil tornam explícito o perfil da mulher privada de liberdade no país: em sua maioria jovem, negra, com baixa escolaridade e mãe². Em 2014, de maneira inédita, foi lançada uma versão do INFOPEN exclusivamente sobre a população prisional feminina, trazendo dados alarmantes, como o crescimento exponencial de $567 \%$ de mulheres presas no país entre os anos 2000 e 2014. Quatro anos depois, surge a segunda edição do INFOPEN Mulheres, com dados atualizados e mais abrangentes, referentes a junho de 2016, acerca das mulheres que cumprem pena no Brasil e os estabelecimentos em que se encontram.

Com relação à idade da população prisional brasileira, o último INFOPEN, mencionado acima, traz a informação de que $55 \%$ da população carcerária é formada por jovens de até 29 anos. A população de jovens entre 18 e 29 anos $^{3}$ corresponde a $18 \% 4$ da população brasileira e $55 \%$ da população prisional no mesmo ano. Se restringirmos os dados apenas à população prisional feminina, a taxa de mulheres jovens corresponde a 50\%. As chances de mulheres de até 29 anos serem presas no Brasil é 2,8 vezes maior se comparado com a probabilidade de mulheres acima de 30 anos serem presas. Existem 101,9 jovens de até 29 anos presas para cada 100.000 mulheres brasileiras maiores de 18 anos (BRASIL, 2018).

No que concerne à maternidade, o INFOPEN Mulheres (2018) obteve dados de apenas 7\% da população prisional feminina. Alguns estados como o Rio de Janeiro, Sergipe e Distrito Federal não dispunham de nenhuma informação sobre o quantitativo de filhos (as) das mulheres e homens privados de liberdade. Os dados acessados apontam que $74 \%$ das mulheres afirmam ter ao menos um filho (a), enquanto $47 \%$ dos homens se encontram na mesma situação (BRASIL, 2018). Esta disparidade estatística pode ser explicada pela responsabilização da maternidade ser atribuída de forma desproporcional entre homens e mulheres, por conta de a atividade do cuidado ser historicamente regida pelo sexo, inclusive de forma racializada. A ausência desses dados (ou a falta de acesso a eles), tende

\footnotetext{
${ }^{2}$ Esses dados são disponibilizados pelo Departamento Penitenciário Nacional (DEPEN) e Ministério da Justiça e Segurança Pública através do Levantamento Nacional de Informações Penitenciárias (INFOPEN), que compila dados estatísticos do sistema penitenciário brasileiro desde 2004.

${ }^{3}$ BRASIL. Lei $n^{\circ} 12.852$, de 5 de agosto de 2013. Institui o Estatuto da Juventude e dispõe sobre os direitos dos jovens, os princípios e diretrizes das políticas públicas de juventude e o Sistema Nacional de Juventude SINAJUVE. Diário Oficial da União, Brasília, DF, 5 ago. 2013.

${ }^{4}$ IBGE. Pesquisa Nacional por Amostra de Domicílios (PNAD) 2015. Disponível em: https://www.ibge.gov.br/ Acesso em: 18 mar. 2019.
}

Temporalis, Brasília (DF), ano 19, n. 38, p. 196-211, jul./dez. 2019. | ISSN 2238-1856 


\section{temporolis}

a não contribuir para análises acerca das configurações familiares de pessoas em privação de liberdade no país, impedindo discussões mais densas e a formulação de políticas voltadas à garantia de direitos dessa população.

No que refere à escolaridade, $65 \%$ da população prisional feminina não acessou o ensino médio, sendo que das integrantes deste grupo, apenas $15 \%$ concluiu o ensino fundamental. Alguns estados evidenciam conjunturas extremas com relação ao acesso à educação, em Alagoas e Rio Grande do Norte a taxa de mulheres privadas de liberdade analfabetas é de 20\%, enquanto no Espírito Santo e na Bahia há o maior contingente de mulheres que acessaram ou concluíram o ensino médio (BRASIL, 2018).

Quanto aos crimes pelos quais essas mulheres respondem, é evidenciado que, majoritariamente, são praticados sem violência, relacionados ao tráfico de drogas, seguido de crimes contra o patrimônio, entre outros registros. A maioria das mulheres responde por crimes ligados ao tráfico de drogas, totalizando $62 \%$, podendo-se afirmar que a proporção de mulheres que respondem por crimes relacionados ao tráfico de drogas no Brasil são de 3 a cada 5 (BRASIL, 2018). A partir deste quantitativo, pode-se observar a preponderância de determinados crimes no que condiz à punição de mulheres pelo sistema de justiça, demonstrando uma seletividade penal que também incide sobre determinados tipos de crimes (a saber: relacionados ao tráfico de drogas e contra o patrimônio). A respeito do grande índice de mulheres que respondem por tráfico de drogas, Dina Alves discorre que

\footnotetext{
Embora a população carcerária feminina seja historicamente menor do que a masculina, pode-se dizer que há uma feminização da punição, principalmente no que diz respeito a crime de tráfico de drogas. A maioria delas ocupa uma posição coadjuvante no crime, realizando serviços de transporte de drogas e pequeno comércio; muitas são usuárias, sendo poucas as que exercem atividades de gerência do tráfico. Elas são moradoras da periferia, responsáveis pela provisão do sustento familiar, com baixa escolaridade, oriundas de extratos sociais desfavorecidos economicamente e exerciam atividades de trabalho informal em período anterior ao aprisionamento (ALVES, 2017, p. 104).
}

Os aspectos evidenciados por Alves na citação acima, revelam a expressão de classe e "raça" na segregação de territórios e como isso influencia nas condições de vida dos sujeitos, especialmente das mulheres. Grupos sociais historicamente com acessos negados ou limitados à educação e ao trabalho demonstram, ainda hoje, serem mais suscetíveis à punição do sistema de justiça, o que configura a reprodução dessas opressões estruturais na lógica punitiva do Estado brasileiro.

De acordo com Mariana Barcinski (2009) são poucos os estudos da criminologia que versam sobre a participação feminina em atividades criminosas e, quando isso ocorre, normalmente esses associam tal participação ao relacionamento de mulheres com homens envolvidos em atividades delituosas, subordinando-as à criminalidade masculina. Ann Goetting (1988) pontua que a falta de visibilidade à criminalidade feminina pode ser relativa à construção dos papéis sociais designados às mulheres, que na maioria das vezes as colocam enquanto vítimas e não como possíveis protagonistas de práticas consideradas criminosas. Em pesquisa realizada com mulheres envolvidas com o tráfico de drogas no Rio de Janeiro (BARCINSKI, 2009), foi constatado que gênero é um determinante central na forma como as mulheres constroem suas participações no tráfico de drogas, sendo ou não 
sua participação, uma consequência de prévia relação com homens envolvidos com o tráfico, essas mulheres ocupavam cargos inferiores aos homens.

[...] ser pobre, negra e favelada restringe as possibilidades de mulheres dentro e fora da rede do tráfico de drogas. Apesar do caráter transgressivo da atividade na qual as participantes estiveram envolvidas, suas experiências passadas como criminosas foram marcadas por uma constante submissão aos homens na atividade. Apesar das participantes terem se sentido superiores a outras mulheres que não tiveram envolvimento com o tráfico de drogas, o poder afirmado foi frequentemente experimentado dentro dos limites de gênero que caracterizam as experiências de mulheres 'normais' na favela. Como claramente afirmado por uma das participantes, às mulheres é permitido somente um 'certo poder' no tráfico de drogas. (BARCINSKI, 2009, p. 1852).

Como discorrido por Barcinski, mulheres envolvidas com o tráfico de drogas tendem a vivenciar parte de um poder antes experenciado apenas por homens. É fato que nem todas as mulheres envolvidas com o tráfico alçam esse status, mas o poder parcial, ainda submisso aos homens envolvidos com a mesma atividade, é também reflexo de uma sociedade patriarcal que não permite que mulheres tenham acesso ou visibilidade de forma proporcional como historicamente homens (principalmente os brancos) o têm.

O Projeto Tecer Justiça, realizado pelo Instituto Terra, Trabalho e Cidadania (ITTC) junto da Pastoral Carcerária, traz dados dos anos de 2010 e 2011 de presos (as) provisórios (as) de dois grandes estabelecimentos prisionais da cidade de São Paulo: o Centro de Detenção Provisória I de Pinheiros e a Penitenciária Feminina de Sant'Ana. Ao questionar as mulheres entrevistadas sobre seus vínculos com o mercado de trabalho, anteriores à prisão, 61,1\% alegaram que estavam trabalhando antes de serem presas, a maioria desenvolvia atividades que exigem baixa ou nenhuma qualificação, relacionadas principalmente a atividades domésticas, como diarista, doméstica e faxineira (17,9\%); 14,4\% destas mulheres declararam não ter ocupação anterior ao ato de prisão e 8,3\% afirmaram ser dona de casa (CERNEKA et al., 2012). Da população de mulheres atendidas pelo referido Projeto, 72,6\% revelaram ter trabalho informal no momento anterior à prisão, e destas, 59,3\% contribuíam para o sustento da família. Com relação a renda familiar, o Projeto demonstrou que as mulheres em situação de prisão apresentam renda inferior se comparada com a dos homens em igual situação: para ganhos familiares de até um salário mínimo, 41,6\% das mulheres e $27,9 \%$ dos homens declararam se situar nessa faixa de renda; entretanto, na faixa entre um a três salários mínimos, $33,8 \%$ das mulheres e $42,2 \%$ dos homens alegaram estes ganhos.

Embora não fora encontrado dados similares, em nível nacional, que demonstrem a condição de trabalho anterior à prisão de mulheres encarceradas, os dados obtidos pelo Tecer Justiça reproduzem a condição majoritária de mulheres presas no país: a incidência da baixa escolaridade. A baixa escolaridade tende a limitar as oportunidades de inserção no mercado de trabalho. O trabalho informal, desprovido de proteção social e garantia de direitos trabalhistas, não é exclusivo às mulheres, porém, com a histórica divisão sexual do trabalho e a prevalência de mulheres em ocupações direcionadas a serviços pessoais (como os serviços domésticos, de cuidado, entre outros), que possuem alto grau de informalidade e precarização, situam as mulheres em uma condição de desigualdade e maior vulnerabilidade em relação ao emprego e a renda, se comparada com os homens. 
Concordamos com Danièle Kergoat quando define a divisão sexual do trabalho como a "[...] forma de divisão do trabalho social decorrente das relações sociais de sexo [...]" que "[...] tem por características a destinação prioritária dos homens à esfera produtiva e das mulheres à esfera reprodutiva e, simultaneamente, a ocupação pelos homens das funções de forte valor social agregado" (KERGOAT, 2012, p. 214). Anne-Marie Devreux complementa que a divisão sexual do trabalho "[...] articula os campos do trabalho produtivo e do trabalho reprodutivo [excluindo-os ou integrando-os] segundo o momento e as necessidades dominantes" (DEVREUX, 2011, p. 12-13). Entretanto, como destaca Mirla Cisne (2018), ao abordar divisão sexual do trabalho é necessário compreender que diversos elementos compõe as relações sociais de sexo (orientação sexual, identidades de sexo e etc.) e que estas estão diretamente associadas à divisão racial do trabalho, pois existem desigualdades entre as mulheres, afinal, mulheres também exploram mulheres.

Em relação a "raça", cor ou etnia da população prisional feminina, o INFOPEN Mulheres (BRASIL, 2018) aponta que $62 \%$ são negras, $37 \%$ são brancas e o restante é dividido entre amarelas, indígenas e outras. A disparidade entre os padrões de encarceramento de mulheres negras e brancas também é expressa no tocante à população prisional total (homens e mulheres), na qual 64\% de seus integrantes é negra, enquanto que, no mesmo ano, a população de negros/as acima de 18 anos no Brasil era de 53\%, demonstrando uma sobrerrepresentação dessa população no sistema prisional do país (BRASIL, 2017).

Isso não é nenhuma novidade no sistema prisional. Angela Davis (2016), em sua obra Mulheres, Raça e Classe discorre sobre a trajetória da mulher negra nos Estados Unidos pós abolição, revelando que

Por meio do sistema de contratação de pessoas encarceradas, a população negra era forçada a representar os mesmos papéis que a escravidão havia Ihe atribuído. Homens e mulheres eram igualmente vítimas de detenções e prisões sob os menores pretextos - para que fossem cedidos pelas autoridades como mão de obra carcerária (DAVIS, 2016, p. 96).

A mesma autora ainda pontua que as mulheres negras eram mais vulneráveis ao sistema judiciário, por questões relativas ao sexo.

Essa deturpação do sistema de justiça criminal era opressiva para toda população saída da escravidão. Mas as mulheres eram especialmente suscetíveis aos ataques brutais do sistema judiciário. Os abusos sexuais sofridos rotineiramente durante o período da escravidão não foram interrompidos pelo advento da emancipação. (DAVIS, 2016, p. 97).

No contexto brasileiro, Alves relata que

Considerar a vigilância ostensiva e a seletividade penal a que estão submetidas as mulheres negras é muito importante aqui porque os intérpretes da lei (sejam eles policiais, promotores, juízes, advogados, legisladores, administradores, defensores públicos e demais servidores públicos da justiça penal) reproduzem, disseminam e sustentam um regime racial de 'produção de verdade'5, que favorece a produção de provas e a atuação policiva voltada à ampliação do poder penal e ao encarceramento em massa de indivíduos considerados 'suspeitos' (ALVES, 2017, p. 108).

\footnotetext{
${ }^{5}$ FOUCAULT (2004).
} 
Afirmam, Zaffaronni e Batista (2003), que o regime de punição praticado pelo aparato punitivo do Estado brasileiro é herança do passado escravocrata, inerente ao regime colonial, pois tem no corpo negro a concepção de crime e castigo. Isso enseja um Estado de exceção permanente à população negra, onde a lei aparece frequentemente sob a forma de punição. Sendo assim, "[...] a escravidão representa este lugar onde o corpo negro foi (e continua sendo) laboratório de experimentos das tecnologias de economia, punição e morte" (ALVES, 2018, p. 94).

Para Segato (2007), mesmo com a transição de colônia para república, as instituições que representam a justiça penal em toda América Latina, continuam a reproduzir as relações sociais características do regime escravocrata. Na mesma perspectiva, Aguirre (2007) retrata que algumas práticas de punição do período colonial continuaram a ser aplicadas mesmo após a independência de países latinos, e atesta que os líderes desses novos Estados independentes continuavam a perseguir e controlar populações consideradas indisciplinadas e imorais pela elite branca. A permanência de práticas de controle social, racial e laboral, como o alistamento militar obrigatório, o tributo indígena, entre outras, contradiziam com o sistema de igualdade e a lei de cidadania universal que a maioria das constituições dos países latino-americanos prometiam (MALLON, 1992; LARSON, 2004).

O Brasil, com 42.355 mulheres presas, é o $4^{\circ}$ país no ranking mundial com maior população prisional feminina, ficando atrás apenas dos Estados Unidos, China e Rússia (BRASIL, 2018). O aumento da população prisional feminina é observado em nível internacional, em países que adotaram a pena de prisão como resposta à política de guerra às drogas. Entretanto, dentre esses países, o Brasil é o único em que a expansão do aprisionamento feminino é incomparável índices registrados nos demais, pois entre os anos de 2000 e 2016 a taxa de aprisionamento de mulheres aumentou em 455\%, enquanto, no mesmo período, a dos Estados Unidos aumentou em 18\%, da China em 105\% e da Rússia diminuiu 2\%.

A seletividade penal que permeia as prisões brasileiras, evidenciada nos números que caracterizam a população prisional do país, representa as respostas que a democracia branca tem dado às inúmeras expressões da questão social. O Estado vem apostando na criminalização e na punição generalizada de corpos negros e pobres como resposta a ausência de políticas públicas que dêem conta do rastro histórico da desigualdade social no Brasil.

Os dados expostos acima nos permitem afirmar que sexo ${ }^{6}$, "raça" e classe compõe a categoria mulher encarcerada. A maioria das mulheres no país respondem por crimes sem violência, relacionados majoritariamente ao tráfico ou porte de drogas consideradas ilícitas. São mulheres jovens, negras e de baixa escolaridade. Mulheres, em sua maioria, que não tiveram acesso ao mercado de trabalho formal antes de adentrarem a prisão. Essa exclusão do trabalho é reflexo da lógica capitalista, que para sua manutenção e reprodução, necessita de um contingente de trabalhadores desempregados - exército de

\footnotetext{
${ }^{6}$ Optamos pela utilização de sexo em lugar de gênero, pois concordamos com Cisne ao afirmar que o centro da crítica ao conceito de gênero se fundamenta "[...] na ocultação da hierarquia e dos antagonismos materiais existentes entre os sexos. Essa ocultação ocorre porque, hegemonicamente, os estudos de gênero não são desenvolvidos de forma relacional aos sistemas de exploração, notadamente, de classe. Ao contrário, eles tendem à discussão mais individual, da construção cultural e da categorização do ser homem e do ser mulher, por meio de símbolos, das subjetividades, das representações sociais e identidades, deslocando essas dimensões de sua base objetiva e material" (CISNE, 2018, p. 50).
}

Temporalis, Brasília (DF), ano 19, n. 38, p. 196-211, jul./dez. 2019. | ISSN 2238-1856 
reserva - para o processo de produção, o que impacta diretamente na redução dos padrões salariais e demais direitos trabalhistas, aos quais os/as trabalhadores/as se vêem constrangidos a abdicar em nome da empregabilidade. A prisão torna-se o que Wacquant (2001) define como “depósito de indesejáveis", ou seja, de uma população que além de ser considerada como desviante e perigosa, é supérflua ao plano econômico e político. Reconhecer a "raça" enquanto categoria da estrutura penal brasileira é compreender que, embora seja nítido que a pobreza seja característica da maioria da população carcerária, a "raça" também é evidenciada de forma exorbitante. Conforme Davis em As mulheres negras na construção de uma nova utopia, "classe informa a raça", mas "raça, também informa classe", "raça é a maneira como a classe é vivida", assim como "gênero é a maneira como a raça é vivida". Determinados grupos raciais são mais vulneráveis à punição do Estado do que outros, e, parafraseia-se Alves (2017), pois concorda-se integralmente com sua expressão de que "[...] a justiça penal é um lugar privilegiado de reprodução das desigualdades raciais" (ALVES, 2017, p. 106).

No próximo item busca-se apreender a atuação do Estado, através do sistema prisional, no encarceramento de mulheres no Brasil, a partir da punição acentuada por determinantes socioeconômicos que se mostram mais vulneráveis à condenação do Estado penal e evidenciada pelas condições em que a prisão se materializa para essa população de mulheres.

\section{ESTADO PENAL MÁXIMO E A PUNIÇÃO DE CORPOS NÃO HEGEMÔNICOS}

De fato, as opressões vivenciadas por mulheres não se resumem apenas pela questão de gênero ou sexo, mas também pela classe, "raça"/etnia, orientação sexual, etc. No que se refere a gênero, cabe reforçar que se trata de uma construção social, assim expressa por Heleieth Saffioti,

O gênero é uma maneira de existir do corpo e o corpo é uma situação, ou seja, um campo de possibilidades culturais recebidas e reinterpretadas. Nesta linha de raciocínio, o corpo da mulher, por exemplo, é essencial para definir sua situação no mundo. Contudo, é insuficiente para defini-la como mulher. Esta definição só se processa através da atividade desta mulher na sociedade. Isto equivale a dizer, para enfatizar, que o gênero se constrói-expressa através das relações sociais. (SAFFIOTI, 1992, p. 191, grifo nosso).

Diante disso, podemos afirmar que o gênero/sexo, enquanto categoria sócio-histórica, articulado com demais determinantes condiciona direta e indiretamente as mais variadas experiências das sujeitas em sociedade. Essas determinações não podem ser vistas isoladamente, uma vez que, por mais que elas unam mulheres de acordo com suas especificidades, a classe irá dividi-las, pois, a classe determina como essas opressões irão ser vivenciadas por mulheres (CISNE, 2005). A pesquisadora Heleieth Saffioti (2004) propõe analisar as diversas condições que atuam sobre os indivíduos de forma enovelada, como se estivessem enlaçadas em um nó, pois é certo que essas condições não atuam isoladamente, mas sim de maneira dinâmica, condicionadas pelas variadas realidades. Tal dinâmica é ratificada na exposição de Audre Lorde (2003, p. 19), transcrita a seguir.

Ambas pertencemos a comunidade de mulheres, mas o racismo é um fator que afeta a minha vida e não a sua [...] a opressão sofrida por mulheres não conhece fronteiras étnicas nem raciais, é certo, mas isso não significa que seja idêntica para todas [...] referir-se a uma sem ocupar-se das outras equivale a distorcer tanto o 

apesar da irmandade entre as mulheres. (LORDE, 2003, p. 19, Tradução nossa).

Concorde os dados citados no item anterior, a mulher encarcerada hoje no Brasil possui "raça", classe e idade bem definida. Esse perfil característico da maior parte da população prisional feminina e as condições em que o cárcere se materializa às mulheres parece não ser característico apenas do Brasil. Davis (2003) relata a similitude das prisões femininas ao redor do mundo - "[...] me senti como se estivesse no mesmo lugar. Não importa o quão longe eu viajasse através do tempo e do espaço de 1970 a 2000, e da Casa de Detenção feminina em Nova lorque (onde eu mesma estive presa) até a prisão feminina em Brasília, Brasil" (DAVIS, 2003, p. 527).

Ao abordar a discussão sobre o perfil das mulheres encarceradas na maioria dos países ocidentais, Davis aborda que a prisão, enquanto instituição, produz o "[...] tipo de prisioneiro que, por sua vez, justifica a expansão das prisões" (DAVIS, 2003, p. 528). Sob o discurso oficial, que se apresenta e se legitima na lógica de prevenir crimes, têm-se cada dia mais um Estado vigilante, que busca as características do indivíduo considerado criminoso, criando uma modulação do próprio infrator, seu modo de vida, de pensar, seu passado, etc. (FOUCAULT, 1987). Essa modulação do ser infrator tende a contribuir para a construção de sujeitos mais passíveis de punição, justificando e naturalizando o aprisionamento em massa de determinados indivíduos em detrimento de outros, como acontece com a população negra que é, atualmente, a maioria nas prisões do país.

Historicamente, os estabelecimentos penais femininos no Brasil aprisionam mulheres que não correspondem à feminilidade branca imposta pela elite burguesa. Desde a criação de presídios exclusivamente femininos no país, a partir da promulgação do Código Penal de 1940, prende-se mulheres consideradas transgressoras da ordem moral vigente: as que desacatavam pai ou esposo, as prostitutas, lésbicas, pobres, etc., aquelas que, de certo modo, apresentavam riscos à ordem capitalista patriarcal (ANGOTTI, 2011).

Havia separação nas celas de acordo com o caráter e grupo familiar do qual a mulher provinha, mulheres consideradas de boa família não mantinham contato com mulheres consideradas transgressoras, como prostitutas e lésbicas. A intenção era reeducar essas mulheres aprisionadas para que pudessem retornar a seus lares e estarem aptas a desempenhar seus papéis de cuidadoras do lar, as solteiras eram induzidas a seguir como freiras.

As freiras administraram os presídios femininos até meados de 1980 (ANGOTTI, 2011), e isso não é uma característica exclusiva do Brasil, diversos países da América Latina passaram pelo mesmo processo. É perceptível o apelo moral do cárcere feminino em sua gênese, dotado do forte discurso conservador a partir da divisão sexual do trabalho e dos papéis sociais atribuídos de acordo com o sexo.

A prisão, na democracia branca, continua a aprisionar corpos de mulheres que não correspondem à hegemonia burguesa, mulheres negras, pobres, compõem as celas das prisões brasileiras. Conforme Alves (2017, p. 92) "O período pós-abolição demarcou essa continuidade de sujeição, subordinação e desumanização das mulheres negras, reatualizado nas estatísticas da morte, no emprego doméstico, na favela e nas prisões". 
A sociedade, principalmente sob a forma do Estado, continua a violentar, das formas mais variadas possíveis, corpos historicamente explorados pela elite burguesa, que se utiliza da violência para manutenção de sua hegemonia. Foucault (2008) ressalta que é necessário “[...] mostrar que as medidas punitivas não são simplesmente mecanismos 'negativos' que permitem reprimir, impedir, excluir, suprimir: mas que elas estão ligadas a toda uma série de efeitos positivos e úteis que elas têm por encargo sustentar[...] (FOUCAULT, 2008, P. 27)", como a reprodução dos privilégios históricos da branquitude. Privilégios estes que mantém o poder a partir de critérios de racialidade7, onde pessoas brancas tem maior acesso a educação, trabalho, etc., e também passam mais despercebidos pelo crivo do sistema penal. Isto é evidenciado tanto nos dados sobre encarceramento, que revelam a grande massa de corpos negros aprisionados, como também nos índices de violência, que demonstram o genocídio da população negra e periférica no Brasil $^{8}$, como também o aumento da taxa de feminicídio de mulheres negras ${ }^{9}$. Quanto a isso, Charles Wade Mills torna nítido, a partir de sua descrição do contrato racial define que

[...] uma sociedade organizada racialmente, um Estado racial e um sistema jurídico racial, [é aquele] onde o status de brancos e não-brancos é claramente demarcado, quer pela lei, quer pelo costume. E o objetivo desse Estado, em contraste com o estado neutro do contratualismo clássico, é, inter alia, especificamente o de manter e reproduzir essa ordem racial, assegurando os privilégios e as vantagens de todos os cidadãos integrais brancos e mantendo a subordinação dos não-brancos. (MILLS, 1997, p. 13-14, grifo nosso).

Foucault (1979) afirma que todo corpo é político e que sobre ele incidem as relações de poder. Concomitante a esse pensamento, pode-se afirmar que todo preso é um preso político, diante da historicidade e materialidade da prisão no Brasil, caracterizada pelo aprisionamento em massa da população negra, criminalização da pobreza e ambiente propício à agudização das mais variadas opressões da sociabilidade capitalista. O passado de um país colonizado, que não garantiu (e nem garante) acesso aos mínimos sociais para a maior parte da classe trabalhadora ${ }^{10}$, que carece do acesso ao mercado de trabalho como também de políticas públicas e sociais, é o mesmo país que tem no aparelho punitivo do Estado, a resposta para conflitos, principalmente quando os réus são pobres e negros.

O crime é uma construção social, assim como o discurso punitivo que delineia o(a) criminoso(a), também o é. A construção daquilo que é ilegal, dos chamados delitos e crimes é tratada por Foucault (1987, p. 107) como "[...] economia das ilegalidades [...]" que "[...]

\footnotetext{
${ }^{7}$ A racialização da população (negra e indígena), produto da branquitude, contribuiu e contribui para os processos de marginalização e exclusão de certos grupos sociais para o provimento da hegemonia branca. Concorde Cisne, "como um país de história colonial, que sofreu a dominação de outros povos, a nossa formação sócio-histórica carrega uma substância patriarcal, sexista e racista sem as quais se torna impossível compreender a complexidade das classes sociais do país" (CISNE, 2018, p. 104).

8 Para mais informações consultar o Atlas da Violência 2018, disponível em: http://www.ipea.gov.br/portal/images/stories/PDFs/relatorio_institucional/180604_atlas_da_violencia_2018. pdf e Relatório final da Comissão Parlamentar de Inquérito do Assassinato de Jovens (CPIĀDJ), disponível em: $\quad$ https://www12.senado.leg.br/noticias/arquivos/2016/06/08/veja-a-integra-do-relatorio-da-cpi-doassassinato-de-jovens.

${ }^{9}$ O Atlas de Violência 2018 traz que a taxa de homicídio de mulheres negras cresceu 29,9\%, enquanto o de mulheres não negras cresceu em 4,5\%.

${ }^{10}$ Dados coletados pelo Instituto Brasileiro de Geografia e Estatística (IBGE) de 2017 trazem que 50 milhões de brasileiros vivem na linha de pobreza, com relação a crianças de 0 a 14 anos de idade, $42 \%$ se enquadram nestas condições. Entre as pessoas com menor rendimento no país, $78,5 \%$ são negras, que também se encontram no maior índice de trabalhadores desempregados.
}

Temporalis, Brasília (DF), ano 19, n. 38, p. 196-211, jul./dez. 2019. | ISSN 2238-1856 
se reestruturou com o desenvolvimento da sociedade capitalista" (FOUCAULT, 1987, p. 107). O autor afirma que uma série de práticas criam o que ele chama de "regime de verdade", que fazem com que coisas que não existem, como a delinquência/criminalidade, se tornem uma "coisa", apesar de continuarem a não existir, formando um dispositivo de "saber-poder" (FOUCAULT, 2008), que marca como real aquilo que não existe, atuando legitimamente na construção de verdades que incidem e determinam a vida de sujeitos.

As prisões, no geral, são ambientes propícios de manifestação e prática de opressões. No Relatório Tortura em tempos de encarceramento em massa produzido pela Pastoral Carcerária (2018), são apresentados 105 casos de tortura e maus tratos realizados nas carceragens do país, demonstrando que a tortura faz parte da estrutura das prisões brasileiras. Em 2010, outros casos de tortura que envolviam agentes penitenciários e policiais foram divulgados pela organização Human Rights Watch. Segundo Alves (2018), o relatório explicitava que "[...] as denúncias envolviam espancamentos, agressões físicas, uso de choques elétricos no corpo, sufocamento com sacos plásticos, violência sexual, psicológica, afogamentos em privadas com fezes, ingestão de parafina, entre outros métodos" (ALVES, 2018, p. 95).

Gabrielle Nascimento (2018), relata que mulheres que não correspondem com a feminilidade imposta pela divisão social entre os sexos tendem a sofrer mais violências dentro da prisão.

É comum ouvir nas visitas às unidades prisionais femininas em todo o Brasil que, nas intervenções das tropas de elite, os agentes frequentemente espancavam mais as mulheres que não atendiam às expectativas sociais em torno do gênero feminino com falas como "você quer ser homem, então irá apanhar como um homem", correspondendo aos anseios de normatização cisheterossexual. (NASCIMENTO, 2018, p. 50).

A justiça penal contribui para a reprodução das desigualdades sociais, assim como para a agudização de opressões, tendo como enfoque determinados estereótipos de sujeitos puníveis. Destarte, “[...] racializar e sexualizar as análises sobre estas dimensões da punição pode apontar um entendimento mais profundo sobre a herança da escravidão e da cidadania penal no Brasil hoje" (ALVES, 2018, p. 99). Essas opressões, com base principalmente na "raça", na classe social, no sexo/gênero na sexualidade, são evidenciadas não somente no aparato judicial do Estado, mas também nas maneiras em que esse mesmo Estado "[...] organiza, facilita e sanciona padrões de vulnerabilidade" (ALVES, 2018, p. 99-100). Esse "estado de coisas" como reconheceu o Supremo Tribunal Federal"1 reproduz, nos dias atuais, a lógica do sistema colonial, através de uma "[...] colonialidade da justiça [...]" (SEGATO, 2007), que determina quem terá acesso a direitos e quem os terá como violado.

As prisões e as práticas punitivas não se mantêm sozinhas, são necessários um discurso e a manutenção de uma cultura punitiva que perpassa os aparelhos de punição. A

\footnotetext{
${ }^{11}$ Arguição de Descumprimento de Preceito Fundamental n. 347 MC-DF (ADPF 347), julgada pelo Supremo Tribunal Federal (STF) em setembro de 2015, reconheceu que a realidade prisional no Brasil faz parte de um "estado de coisas". Para mais sobre o tema vide:

http://www.stf.jus.br/arquivo/informativo/documento/informativo798.htm

http://redir.stf.jus.br/paginadorpub/paginador.jsp?docTP=TP\&docID=10300665.
}

Temporalis, Brasília (DF), ano 19, n. 38, p. 196-211, jul./dez. 2019. | ISSN 2238-1856 
naturalização da cultura punitiva, assim como a da desigualdade econômica e de opressões estruturais da sociedade, faz com que a existência de prisões se apresente como alternativa indispensável à segurança da sociedade. A ausência de uma análise crítica e histórica das prisões e demais práticas punitivas exercidas pelo Estado, tende a contribuir para a permanência da criminalização da pobreza, do racismo, do sexismo e da LGBTfobia.

\section{CONSIDERAÇÕES FINAIS}

O cenário atual do encarceramento de mulheres no Brasil demonstra de forma nítida a seletividade da instituição penal que criminaliza sujeitos a partir da "raça" e da classe social, contribuindo para a manutenção da criminalização da pobreza e do encarceramento em massa da população negra. Conforme Baratta (2002) a burguesia possui a preocupação em culpabilizar os indivíduos pela ocorrência de crimes e não os reconhece como resultantes da estrutura social.

Em síntese, a pena privativa de liberdade tem como finalidade "[...] reeducar, ressocializar, recuperar, reabilitar, readaptar [...]" o indivíduo considerado criminoso, que é "[...] internado no sistema penal para que de lá saia passível de reintegrar o meio social [...]", pois "[...] não basta castigar o criminoso, há que oferecer no interior das instituições prisionais meios que orientem o indivíduo para que não volte a delinquir" (TORRES, 2008, p. 27). Porém, como preparar um sujeito para a vida em sociedade o isolando? Como arcar com os princípios da ressocialização na condição de superlotação dos presídios brasileiros? A exemplo da taxa de ocupação de mulheres em situação de prisão é de 156,7\%, são 42.355 mulheres aprisionadas para apenas 27.029 vagas nas instituições prisionais (BRASIL, 2018). Para Foucault “[...] desde 1820, constata-se que a prisão, longe de transformar os criminosos em pessoas honestas, só serve para fabricar novos criminosos, ou para enterrar ainda mais os criminosos na criminalidade" (FOUCAULT, 2010, p. 162).

Portanto, longe de ser um espaço de ressocialização e aprendizado,

[...] o novo sistema de controle social do desvio, que a ideologia das teorias liberais racionaliza, como o demonstra a experiência prática, até hoje, dos países capitalistas mais avançados, pode ser interpretado como uma racionalização e uma integração do sistema penal e do sistema de controle social, em geral, com o fim de torná-lo mais eficaz e mais econômico em relação a sua função principal: contribuir para a reprodução das relações sociais de produção. (BARATTA, 2002, p. 150, grifo nosso).

Os debates sobre as prisões tendem a ser referenciados sob perspectivas moralizadoras produzidas historicamente e difundidas pelo senso comum, tendo em vista a manutenção de uma cultura punitiva que dê ensejo a atuação de um Estado penal máximo. Sueli Carneiro (2005) explicita, a partir da noção de dispositivo de Foucault, que o dispositivo de racialidade tem, a partir da cor da pele, a identificação entre o normal e o Outro, tendo a brancura como padrão de normalidade. Para a autora citada, isso coaduna com

[...] o senso comum, segundo o qual a vida dos brancos vale mais do que a de outros seres humanos, o que se depreende, por exemplo, da consternação pública que provoca a violência contra brancos das classes hegemônicas, em oposição à indiferença com que se trata o genocídio dos negros e outros nãobrancos em nossa sociedade. (CARNEIRO, p. 44, grifo nosso). 
É diante da incidência de invisibilidade sobre as pautas do encarceramento em nosso país, marcado e estruturado pelo racismo, silenciado pelo patriarcado, que se marginaliza ainda mais mulheres em situação de cárcere. A prisão, conforme visto, é um ambiente propício para reprodução de opressões que compõem a sociabilidade capitalista brasileira. Em um cenário de intensificação de discursos conservadores, centrados na perpetuação da centralidade hegemônica da família nuclear burguesa e do poder da branquitude, a construção da mulher condenada pelo sistema penal como o Outro (FOUCAULT, 1979), como aquilo que se difere do normal, do esperado, aliados a fortes narrativas meritocráticas, visibilizar essas pautas e apreender a verdadeira dinâmica do Estado penal se mostra urgente para uma categoria profissional, como a de Assistentes Sociais, centrada em construir a luta por emancipação humana.

Em seus escritos, Audre Lorde sempre nos relembra da necessidade de enxergar o que nos difere para a construção de uma sociedade mais igualitária. Em seu texto As ferramentas do mestre não vão desmantelar a casa grande de 1979, ela instrui que,

\begin{abstract}
Como mulheres, nós fomos ensinadas a ignorar nossas diferenças, ou vê-las como causas de separação e suspeita em vez de forças para serem mudadas. Sem comunidade não há libertação, apenas o armistício mais vulnerável e temporário entre um indivíduo e sua opressão. Mas comunidade não deve significar uma queda de nossas diferenças, nem a pretensão patética de que essas diferenças não existem. Aquelas de nós que estão fora do círculo da definição desta sociedade, de mulheres aceitáveis, aquelas de nós que foram forjadas no calvário da diferença - aquelas de nós que são pobres, que são lésbicas, que são negras, que são mais velhas — sabem que sobrevivência não é uma habilidade acadêmica. É aprender como estar sozinha, impopular e às vezes injuriada, e como criar causa comum com aquelas outras que se identificam como fora das estruturas a fim de definir e buscar um mundo no qual todas nós possamos florescer. É aprender como pegar nossas diferenças e transformá-las em forças. Pois as ferramentas do mestre não irão desmantelar a casa do mestre. Elas podem nos permitir temporariamente a ganhar dele em seu jogo, mas elas nunca vão nos possibilitar a causar mudança genuína. E este fato é somente ameaçador àquelas mulheres que ainda definem a casa do mestre como a única fonte de apoio delas. (LORDE, 1979, n.p.).
\end{abstract}

Portanto, concorda-se com lamamoto, quando afirma que "[...] pesquisar e conhecer a realidade é conhecer o próprio objeto de trabalho, junto ao qual se pretende induzir ou impulsionar um processo de mudança" (IAMAMOTO, 1999, p. 62). Isso justifica o debruçar e o esmiuçar sobre as coisas. Coisas tais que se mostram contraditórias, enoveladas por múltiplas determinações que nem sempre se expressam de princípio. Os processos de criminalização discutidos neste trabalho, pautados por determinantes de "raça", sexo e classe, tornam nítida a importância da reflexão e do debate sobre a funcionabilidade da instituição prisional na sociedade do capital. Ao pensar na criminalização de determinadas práticas, se faz necessário, de forma conjunta, crítica e historicizada, refletir a quem a criminalização atinge. Quem, efetivamente, a justiça penal condena. E não se está discorrendo apenas sobre uma seletividade penal que, para tornar-se mais justa, deve-se destinar a todos de forma democrática e igualitária. Estamos falando de uma instituição que, desde sua gênese, marginaliza e estigmatiza quem passar por ela. 


\section{REFERÊNCIAS}

AGUIRRE, Carlos. Prisons and Prisoners in Modernising Latin America (1800-1940). In: DIKÖTTER, Frank; BROWN, Ian (Eds.). Cultures of Confinement. A History of the Prison in Africa, and Latin America. New York: Cornell University Press, p. 14-54, 2007.

ALVES, Dina. O camburão também é feminino: raça e punição feminina na justiça criminal. In: CARCERÁRIA, Pastoral. Tortura em tempos de encarceramento em massa. São Paulo: Pastoral Carcerária, 2018. p. 89-102. Disponível em: https://carceraria.org.br/wpcontent/uploads/2018/12/Tortura-em-tempos-de-encarceramento-em-massa-2018.pdf. Acesso em: 10 mar. 2019.

ALVES, Dina. Rés negras, juízes brancos: Uma análise da interseccionalidade de gênero, raça e classe na produção da punição em uma prisão paulistana. Revista CS, Cali, n. 21, p. 97-120, 2017.

ANGOTTI, Bruna Soares. Entre as leis da ciência, do estado e de deus: o surgimento dos presídios femininos no Brasil. 2011. Dissertação (Mestrado em Antropologia Social) Faculdade de Filosofia, Letras e Ciências Humanas, Universidade de São Paulo, São Paulo, 2011.

BARATTA, Alessandro. Criminologia crítica e crítica do direito penal: introdução à sociologia do direito penal. Rio de Janeiro: Revan, 2002.

BARCINSKI, Mariana. Centralidade de gênero no processo de construção da identidade de mulheres envolvidas na rede do tráfico de drogas. Ciência \& Saúde Coletiva, Rio de Janeiro, v. 14, n. 5, p. 1843-1853, 2009.

BRASIL. Departamento Penitenciário Nacional. Levantamento Nacional de Informações Penitenciárias INFOPEN - Junho de 2016. Brasília (DF), 2018. Disponível em: http://depen.gov.br/DEPEN/depen/sisdepen/infopen-mulheres/infopenmulheres_arte_0703-18.pdf. Acesso em 15 mar. 2019.

BRASIL. Departamento Penitenciário Nacional. Levantamento Nacional de Informações Penitenciárias INFOPEN - Junho de 2016. Brasília (DF), 2017. Disponível em: http://depen.gov.br/DEPEN/depen/sisdepen/infopen/relatorio_2016_22-11.pdf. Acesso em 18 mar. 2019.

BRASIL. Departamento Penitenciário Nacional. Levantamento Nacional de Informações Penitenciárias INFOPEN - Junho de 2014. Brasília (DF), 2014. Disponível em: http://depen.gov.br/DEPEN/depen/sisdepen/infopen-mulheres/relatorio-infopenmulheres.pdf. Acesso em 13 mar. 2019.

CARNEIRO, Aparecida Sueli. A Construção do Outro como Não-Ser como fundamento do Ser. 2005. Tese (Doutorado em Educação) - Faculdade de Educação, Universidade de São Paulo, São Paulo, 2005.

CERNEKA, Heidi Ann et. al. Tecer Justiça: presas e presos provisórios na cidade de São Paulo. São Paulo: ITTC, 2012. 
CISNE, Mirla. Feminismo, Diversidade Sexual e Serviço Social. São Paulo: Cortez, 2018.

CISNE, Mirla. Marxismo: uma teoria indispensável à luta feminista. In: COLÓQUIO MARX E ENGELS, 4., 2005, Campinas. Anais [...]. Campinas- SP, 2005. Disponível em:

http://www.unicamp.br/cemarx/ANAIS\%20IV\%20COLOQUIO/comunica\%E7\%F5es/GT4/gt4m 3c6.PDF. Acesso em: 8 fev. 2019.

CURIEL, Ochy. Identidades essencialistas o construcción de identidades políticas: El dilema de las feministas negras. Otras Miradas, Caracas, v. 2, n. 2, p. 96-113, dec. 2002.

DAVIS, Angela. Mulheres, raça e classe. São Paulo: Boitempo, 2016.

DAVIS, Angela. Are Prison Obsolete? New York: Seven Stories Press, 2003.

DEVREUX, Anne-Marie. A teoria das relações sociais de sexo: um quadro de análise sobre a dominação masculina. Cadernos de Crítica Feminista, ano 5, n. 4, dez. 2011.

FOUCAULT, Michel. Ditos e Escritos IV. Rio de Janeiro: Forense Universitária, 2010.

FOUCAULT, Michel. Nascimento da Biopolítica. Curso no Collège de France (1978-1979). São Paulo: Martins Fontes, 2008.

FOUCAULT, Michel. Verdade e Poder. Microfísica do Poder. Rio de Janeiro: Graal, 2004.

FOUCAULT, Michel. Vigiar e Punir. Petrópolis: Vozes, 1987.

FOUCAULT, Michel. Microfísica do Poder. Rio de Janeiro: Graal, 1979.

GOETTING, A. Patterns of homicide among children. Criminal Justice and Behavior, n. 15, 1988.

IAMAMOTO, Marilda Vilela. O Serviço Social na Contemporaneidade: trabalho e formação profissional. 2 ed. São Paulo: Cortez, 1999.

KERGOAT, Danièle. Se batter, disent-elles... Paris: La dispute, 2012.

LARSON, Brooke. Trials of nation making: liberalism, race, and ethnicity in the Andes, 1810-1910. Cambridge: Cambridge University Press, 2004.

LORDE, Audre. Mulheres negras: As ferramentas do mestre nunca irão desmantelar a casa do mestre. Conferência realizada pela autora na New York University - Institute for the Humanities em 1979. Tradução Renata. Geledés, 10 ago. 2013. Disponível em: https://www.geledes.org.br/mulheres-negras-as-ferramentas-do-mestre-nunca-iraodesmantelar-a-casa-do-mestre/. Acesso em: 02 mar. 2019.

LORDE, Audre. La hermana, la extranjera. Madrid: Horas y Horas, 2003. 
MALLON, Florencia. Indian Communities, Political Cultures and the State in the Latin America. Journal of Latin America Studies, v. 24, Cambridge, 1992.

MILLS, Charles. The Racial Contract. Cornell University, 1997.

NASCIMENTO, Gabrielle. O gir e o corpo negro como laboratório. In: CARCERÁRIA, Pastoral. Tortura em tempos de encarceramento em massa. São Paulo: Pastoral Carcerária, 2018. p. 44-54. Disponível em: https://carceraria.org.br/wpcontent/uploads/2018/12/Tortura-em-tempos-de-encarceramento-em-massa-2018.pdf. Acesso em: 10 mar. 2019.

PASTORAL CARCERÁRIA. Agenda Nacional pelo Desencarceramento. São Paulo: Pastoral Carcerária, 2014. Disponível em: https://carceraria.org.br/wpcontent/uploads/2015/06/Agenda-em-Portugues.pdf. Acesso em: 05 mar. 2019.

SAFFIOTI, Heleieth. Gênero, patriarcado, violência. São Paulo: Fundação Perseu Abramo, 2004.

SAFFIOTI, Heleieth. Rearticulando gênero e classe social. In: COSTA, Albertina de Oliveira; BRUSCHINI, Cristina (Org.). Uma questão de gênero. Rio de Janeiro: Rosa dos Tempos; São Paulo: Fundação Carlos Chagas, 1992, p. 183-215.

SEGATO, Rita. El color de la cárcel en América Latina: apuntes sobre la colonialidad de la justicia en un continente em desconstrucción. Revista Nueva Sociedad, n. 208, p. 142-161, 2007.

TORRES, Sabrina Lopes. Os paradoxos da ação profissional no sistema penal: uma análise do serviço social na penitenciária masculina e no hospital de custódia e tratamento psiquiátrico. 2008. Dissertação (Mestrado em Serviço Social) - Departamento de Serviço Social, Universidade Federal de Santa Catarina, Florianópolis, 2008.

WACQUANT, Loïc. As prisões da miséria. Rio de Janeiro: Jorge Zahar, 2001.

ZAFFARONNI, Eugenio Raúl; BATISTA, Nilo. Direito Penal Brasileiro, Teoria Geral do

Direito Penal. v. 1, Rio de Janeiro, Revan, 2003.

Ana Clara Gomes Picolli Autora do texto.

Graduanda de Serviço Social da Universidade Federal do Paraná, Setor Litoral.

Silvana Marta Tumelero Co-autora e orientadora do trabalho.

Assistente social. Doutora em Serviço Social - UFSC. Professora da Universidade Federal do Paraná - UFPR, com atuação na Câmara de Graduação do Setor Litoral. 